Derivation of the structural relations and comparison with the actual data.

From (c) and equation (1) we have:

$$
V=n l \times \text { a constant }
$$

Since the mean concentration of total nitrogen in the urine is also, from (c), independent of body size, and introducing the well-known relation of metabolism to body surface, we derive :

$$
n l=W^{0.666} \cdots \times \text { a constant . . }
$$

From $(a)$ we have directly that the secreting cells are independent of the size of the animal, or :

$$
d=W^{0.000} \times \text { a constant . . . }
$$

The mass of the secreting tissue will be proportional to $n l \times d^{2}$ and since $d$ is constant, from equation (4), the mass is therefore proportional to $n l$. Since from (b) $l$ will be a linear dimension of this secreting tissue, we get from (3):

and

$$
n=W^{0.444} \times \text { a constant . . . }
$$

$$
l=W^{0.222} \times \text { a constant }
$$

From the first principle $(a)$, and equations (2) and (3), it follows that:

$n g^{2}=V \times$ a constant $=W^{0.666} \times$ a constant

where $g$ is the diameter of the glomerulus.

Hence from (5) we get :

$$
g=W^{0.111} \times \text { a constant. }
$$

Collecting the theoretical relations for the single measurements, we have :

$$
\begin{aligned}
& n=W^{0.444} \times \text { a constant } \\
& l=W^{0.222} \times \\
& g=W^{0 \cdot 111} \times, \\
& d=W^{0.000} \times,
\end{aligned}
$$

The actual relations established by the minimum square error principle from the logarithmic values of measurements on the mouse, rat, rabbit, cat, echidna, dog, sheep, pig, man, horse and cow, from the available data of Peter, Putter, Inouye, Siewart, Moberg, O'Connor and Conway, etc., are :

$$
\begin{aligned}
& n=4580 W^{0.456} \\
& l=1.78 W^{0.196} \\
& g=55 W^{0.109} \\
& d=50 W^{0.006}
\end{aligned}
$$

where $l$ is length of first convoluted tubule expressed in millimetres and $g$ and $d$ are expressed in microns.

It 'is hoped to present details shortly in the Proceedings of the Royal Irish Academy.

University College,

EDWARD J. CONWAY.

Dublin. Jan. 7.

${ }^{1}$ See Conway, E. J., and Kane, F., 'J. Physiol., 61, 595 (1926); Conway, E. J., Amer. J. Physiol., 88, i (1929).

\section{Claims of Geology in School Courses of General Science}

ThE Interim Report of the Sub-Committee of the Science Masters' Association on "The Teaching of General Science" (reviewed in NATuRE of December 19 ; 138, 1030) will have been read with much appreciation by all who are interested in school science. While this is under discussion it seems appropriate to direct attention to another report, on
"The Teaching of Geology in Schools", by a Committee of Section C of the British Association. This latter report will appear in the forthcoming annual volume of the British Association, but unfortunately it was not available in time for consideration by the Science Masters' Sub-Committee. In it, amongst other recommendations, is a strong plea for the inclusion of a certain amount of geology (with physics, chemistry and biology) in all courses of general science. The Science Masters' Sub-Committee decided not to include any geology (or astronomy) in the syllabuses they suggested, "despite their obvious claims to inclusion". This decision will be regretted, at any rate by geologists, but it may be hoped that it is not final. Indeed the definition of general science arrived at by the Sub-Committee encourages the hope that the claims of geology can scarcely be overlooked : it begins, "General science is a course of scientific study and investigation which has its roots in the common experience of children and does not exclude any of the fundamental sciences".

It is perhaps not yet generally recognized that many geologists regard the present outlook for their subject with grave disquiet, for although geology has never been taught in sehools so widely as other sciences, its position in the educational system has recently become far worse than in the past. It is claimed that there are both cultural and utilitarian grounds for teaching it in schools of all types, but the absence of any mention of it in most curricula is leading to a scarcity of students which threatens to affect seriously the quality of professional geologists and to react adversely on teaching and research in the science.

It may, of course, be held that this position is not the concern of the schoolmaster, but it is noteworthy that the Sub-Committee of the Science Masters' Association takes a wider view of the teacher's responsibilities. While it is suggested that the training of experts cannot form a part of a school course, "the pre-preparation of experts" is one of the schoolmaster's tasks, "and this can best be achieved by broadening the syllabus; for it is at school that particular talents are discovered and their development fostered".

It is hoped that the position of geology in schools, in general science as well as in other courses, may receive sympathetic consideration in the light of the recommendations put forward in the report of the Committee of Section C, for it may be doubted whether one per cent of those who at school receive some training in science have an opportunity to discover any talent for work in geology.

University of Bristol.

A. E. Trueman. Jan. 18

The Hexlet

IN Prof. Soddy's recent article ${ }^{2}$, the following expression occurs under the root sign in formula (2):

$6(\alpha \beta+\beta \gamma+\gamma \alpha+\alpha \delta+\beta \delta+\gamma \delta)-3\left(\alpha^{2}+\beta^{2}+\right.$ $\left.\gamma^{2}+\delta^{2}\right)$.

I find that this expression is equal to $27 V^{2} \alpha^{2} \beta^{2} \gamma^{2} \delta^{2}$, where $V$ is the volume of the tetrahedron whose vertices are at the centres of the four spheres with bends $\alpha, \beta, \gamma$ and $\delta$.

Prof. Soddy, on hearing of this relation, suggested to me that the expression might (following the analogy of the inscribed circle in two dimensions) be related to the bend of the inscribed sphere. This does not turn out to 